\title{
The effects of age and water/cement ratio upon the relation between ultrasonic pulse velocity and compressive strength of concrete*
}

\author{
by M. F. Kaplan, Ph.D., B.Sc.(Eng.), B.A., B.Com., A.M.I.C.E., A.M.I.Struct.E., A.M.(S.A.).I.C.E.
}

Contribution by T. N. W. Akroyd,

LL.B., M.Sc.(Tech.), A.M.I.C.E., A.M.I.Struct.E. (Constructional Services Ltd)

My comments refer less to the actual results obtained by Dr Kaplan from his test than to the fact that results obtained in the laboratory rarely, if ever, can be applied to tests carried out on actual concrete structures. At the time of the meeting(1) held at University College in 1956, I was of the opinion that it should be possible to obtain an absolute correlation between compressive strength and pulse velocity for one type of concrete made on one site, so long as the effects of the aggregate and the cement used were known. I am coming to the conclusion, however, that there is little, if any, connexion between the ultrasonic pulse velocity in a structure and the strength of concrete cube specimens.

It has been my experience that the ultrasonic pulse velocity in the structure is always appreciably less than that which would be expected from laboratory tests. A brief perusal of the information given by Dr Kaplan in his first four graphs indicates that for strengths of $4,000 \mathrm{lb} / \mathrm{in}^{2}$ ultrasonic pulse velocities in the region of $16,000 \mathrm{ft} / \mathrm{s}$ may be expected. In actual structures, however, for strengths of $4,000 \mathrm{lb} / \mathrm{in}^{2}$ the ultrasonic pulse velocity may at times be as low as $13,000-14,000 \mathrm{ft} / \mathrm{s}$ and it is quite common to find that normal reinforced concrete structures have ultrasonic pulse velocities lower than this and are still considered satisfactory.

That the results of tests on cubes or cylinders are not directly applicable to tests on structures was illustrated by our experience on one job where ultrasonic pulse velocities were measured transversely across a beam. Velocities of $11,780 \mathrm{ft} / \mathrm{s}$ were obtained. At the point where the velocities had been measured a 6 in. diameter core was cut through the beam; the velocity through it was measured and found to be $12,850 \mathrm{ft} / \mathrm{s}$. It was thought that the difference in velocity might be due to the water introduced into the core specimen during the cutting with the diamond bit and a specimen was therefore taken back to the laboratory and soaked completely in water after which a reading of $12,770 \mathrm{ft} / \mathrm{s}$ was obtained. The specimen was then dried thoroughly at $100^{\circ} \mathrm{C}$ and a reading of $12,600 \mathrm{ft} / \mathrm{s}$ obtained. No hypothesis is advanced to account for this but it may well be that the mass of a concrete beam hass some affect on the path and hence the

*Pages 85-92 of Magazine No. 32. velocity of the ultrasonic pulse. Certainly within a 6 in. core the path is restricted.

Dr Kaplan is not alone in putting forward results which do not agree with those obtained in practice. Jones and Gatfield ${ }^{(2)}$ give information of a similar nature to that now given by Dr Kaplan but, until we can obtain results which correspond with those obtainable in the field, the effect of age and water/cement ratio upon the ultrasonic pulse velocities as measured in the laboratory is only of academic interest and has little, if any, practical value. I have found that one of the most dangerous things to do when dealing with ultrasonic pulse velocities is to extrapolate any result to a new set of conditions, so that, as yet, Dr Kaplan's results cannot be applied to our site work.

\section{Reply by the author}

$\mathrm{Mr}$ Akroyd's comments are of considerable interest. I cannot agree, however, with the general statement that " there is little, if any, connexion between ultrasonic pulse velocity in a structure and the strength of concrete cube specimens ". In a recent paper ${ }^{(3)}$ I have given the results of tests on a series of columns and it will be seen that a great deal depends on the history of the concrete cube specimens. The relations between velocity and strength for cubes cured under site conditions gave, for example, a better indication of the strength of concrete in the columns than did the relations for cubes cured in the laboratory.

Pulse velocities in the concrete in a structure may be less than those in specimens made in the laboratory for many reasons, e.g. lower moisture content, less compaction, shrinkage cracks.

I have found ${ }^{(4)}$ that the pulse velocity through the 20 in. length of $20 \times 4 \times 4$ in. beams tends to be less than that through the 4 in. width but considerably more work is required to establish whether the shape and size of concrete test specimens has a significant effect on pulse velocity.

As Mr Akroyd indicates, it may be dangerous to extrapolate ultrasonic pulse velocity results to a new set of conditions. I am of the opinion, however, that greater knowledge of the factors affecting the relation between pulse velocity and strength will assist in a more accurate interpretation of the data obtained in the testing of concrete by the ultrasonic pulse technique. 


\section{REFERENCES}

1. Discussion at University College, London, on the ultrasonic testing of concrete, 1955. Reported in the Magazine of Concrete Research. Vol. 8, No. 24. November 1956. pp. 165-166.

2. JONES, R. and GATFIELD, E. N. Testing concrete by an ultrasonic pulse technique. London, H.M.S.O., 1955. pp. vi, 48. Road Research Technical Paper No. 34.
3. KAPLAN, M. F. Compressive strength and ultrasonic pulse velocity relationships for concrete in columns. Journal of the American Concrete Institute. Vol. 29, No. 8. February 1958. pp. 675-688.

4. KAPLAN, M. F. Ultrasonic pulse velocity, dynamic modulus of elasticity, Poisson's ratio and the strength of concrete made with thirteen different coarse aggregates. RILEM Bulletin. No. 1 (New series). March 1959. pp. 59-73. 